УДК 552.52; 552.08; 553.611

\title{
ИНДИКАТОР Ge/Si ДЛЯ ОЦЕНКИ ИНТЕНСИВНОСТИ ХИМИЧЕСКОГО ВЫВЕТРИВАНИЯ НА ГРАНИЦЕ ПАЛЕОЦЕНА И ЭОЦЕНА В ДРЕВНЕМ ЗАУРАЛЬСКОМ БАССЕЙНЕ
}

\author{
Смирнов Павел Витальевич1,2, \\ geolog.08@mail.ru
}

\section{Баталин Георгий Александрович³, g@batalin.com}

\author{
Гареев Булат Ирекович 3 \\ bulat@gareev.net
}

\author{
Трифонов Артем Алексеевич ${ }^{3}$, \\ ar3tyrt5y@gmail.com \\ 1 Тюменский государственный университет, \\ Россия, 625003, г. Тюмень, ул. Володарского, 6. \\ 2 Тюменский индустриальный университет, \\ Россия, 625000, г. Тюмень, ул. Володарского, 38. \\ 3 Казанский федеральный университет, \\ Россия, 420008, г. Казань, ул. Кремлевская, 4/5.
}

\begin{abstract}
Актуальность. Диатомиты и их переходные разности, сфрормировавшиеся в условиях палеоцен-эоценового морского бассейна, являются одними из самых широко распространённых в приповерхностном залегании осадочных пород на обширной территории Зауралья. При этом применительно к генетическим аспектам таких пород актуальной остается дискуссия о фундаментальных источниках кремнезема для формирования опал-кристобалитовых отложений. Актуальной задачей остается анализ роли каждого из факторов - континентального выветривания и деятельности апвеллингов - в происхождении горных пород. Соотношение $\mathrm{Ge}$ к Si потенциально может рассматриваться как инструмент расшисровки источника кремнезема в биогенных кремнистых породах, так как германий доставляется в породу путем внедрения в биогенный опал; привнос Ge в породу за счет других источников во время диагенеза несущественен, что делает результаты индикационно ценными.
\end{abstract}

Цель: оценка интенсивности химического выветривания на рубеже палеоцена и эоцена в Зауралье на основе изучения соотношения Ge и Sі в разновозрастных диатомитах.

Методы: полевые исследования, рентгенофрлуоресцентный анализ, масс-спектрометрия с индуктивно-связанной плазмой, сканирующая электронная микроскопия.

Результаты. Работа содержит первые результаты оценки интенсивности химического выветривания на рубеже палеоцена и эоцена в Зауралье с помощью анализа расчетных соотношений германия и кремния в валовых образцах диатомитов и препаратах биокластики, из которых удален глинистый материал. Соотношения $\mathrm{Ge} / \mathrm{Si}$ в препаратах биокластики из палеоценовых (Брусяна) и эоценовых (Ирбитское месторождение) диатомитов отличаются практически двукратно. Полученные значения стоит рассматривать как индикатор, что интенсивность химического выветривания претерпевает на этом рубеже серьезные изменения: интенсивное химическое выветривание, усиление гидрологического цикла в период PETM определили увеличение поставки растворенного кремнезема в морской бассейн при накоплении биокремнистых пород на территории современного Зауралья. Ослабление тектонических движений и пенепленизация суши в пределах Восточно-Уральского обрамления способствовали усилению процессов выветривания. Это обеспечило дополнительный транссрер кремнистого вещества в форме истинных и коллоидных растворов в бассейн седиментации для накопления биокремнистых пород. Объем привноса кремнезема с суши на протяжении относительного короткого периода времени стал более заметен в общем балансе поставляемой в бассейн седиментации кремнекислоты. По этой же причине, т. е. из-за наличия дополнительного источника кремнекислоты, валовое содержание $\mathrm{SiO}_{2}$ в палеоценовых диатомитах несколько выше, чем в эоценовых.

\section{Ключевые слова:}

Диатомиты, палеоцен, эоцен, Зауралье, Западная Сибирь, РETM, германий, кремний.

\section{Введение}

Биокремнистые породы - диатомиты и их переходные разности, накапливавшиеся в условиях палеоцен-эоценового морского бассейна, формируют одну из наиболее хорошо диагностируемых, пространственно и литологически выдержанных толщ в составе кайнозойского разреза на обширной территории Зауралья [1-3]. В раннепалеогеновое время на территории Западной Сибири и Зауралья в пределах морского седиментационного бассейна, который существенно влиял на циркуляцию и климатические условия всего Северного полушария и сообщался с Арктическим и Тетическим бассейнами $[4,5]$, в условиях дефицита карбонатного планктона распространение получили различные группы кремнескелетных организмов, среди которых, очевидно, доминирующее положение заняли диатомовые водоросли. Кремнескелетной флоре, вследствие масштабов ее разви- 
тия, принадлежала важнейшая роль в осадкообразовании, в частности в западных краевых зонах эпиконтинентального бассейна, где сформировались мощные толщи диатомитов [6].

Исследования генезиса диатомитов в Зауралье и Западной Сибири имеют существенный прикладной и научный интерес. С одной стороны, этому способствует приуроченность отложений к последнему катастрофическому потеплению на Земле - начальному термальному событию эоцена - палеоцен-эоценовому термическому максимуму (РЕТМ), влияние которого на климат, осадконакопление и состояние биосферы было колоссальным [7-9]. С другой стороны, особое значение принимает тот факт, что на протяжении десятков лет в Зауралье диатомиты являются видом неметаллического сырья, включенным в активную эксплуатацию и потенциально отраслеобразующим для предприятий перерабатывающей промышленности Уральского региона.

Актуальнейшим вопросом при изучении генетических аспектов опал-кристобалитовых пород Зауралья и Западной Сибири остается диагностика источников кремнезема, привнесенного в морской эпиконтинентальный бассейн седиментации и послужившего основой для кремнистых отложений. Эта же задача включает в себя и оценку роли (доминирующей или вспомогательной) каждого из этих факторов в общем балансе привнесенной кремнекислоты. Первые исследователи кремнистых осадочных формаций в регионе в качестве основного фактора рассматривали трансфер кремнезема с пенепленизированных участков суши в виде коллоидных и истинных растворов в седиментационные бассейны [10]. Позже довольно серьезную аргументацию получил тезис, что определяющими факторами широкого развития процессов кремненакопления в платформенных бассейнах раннего кайнозоя являются гидродинамические причины, а именно, развитие зон апвеллингов, в пределах которых обыкновенно осуществляется трансфер обогащенных диоксидом кремнезема глубинных вод [11] Очевидно, определенное место в системе доставки кремнекислоты в седиментационный бассейн может быть отведено гидротермализму и зонам разгрузки минерализованных растворов.

По мере совершенствования геохимических методов исследования осадочных образований было установлено, что в морской среде обыкновенным является сонахождение и замещение кремния (Si) германием $(\mathrm{Ge})$ ввиду близких ионного и ковалентного радиусов и тетравалентной структуры [12-14]. Накопление фактического материала геологами и геохимиками позволило утверждать, что соотношение $\mathrm{Ge} / \mathrm{Si}$ в диатомовых водорослях и производных от них породах может использоваться для мониторинга таких геологических явлений, как континентальное выветривание и гидротермализм. Эти процессы являются главными источниками привноса основных и рассеянных элементов в океан [15-19]. По мнению [20] горные породы концентрируют в себе германий, доставленный в них двумя путями: 1 - из обломочной фракции, привносимой в бассейн в виде осадков, 2 - из биоген- ной фракции, поступающей из морской воды за счет инкорпорации $\mathrm{Ge}$ морскими кремнескелетными организмами (диатомеями, радиоляриями, губками) в твердые части собственных раковин, скелетов или спикул.

Применительно к генетическим аспектам формирования таких пород актуальной остается дискуссия о фундаментальных источниках кремнезема для формирования опал-кристобалитовых пород. Она разворачивается в части оценки одного из двух факторов континентального выветривания и деятельности апвеллингов. В этой связи соотношения $\mathrm{Ge}$ к $\mathrm{Si}$ потенциально могут рассматриваться как инструмент расшифровки источника кремнезема при формировании биогенных кремнистых пород. Германий доставляется в породу путем внедрения в биогенный опал; привнос $\mathrm{Ge}$ в породу за счет других источников во время диагенеза несущественен, что по мере совершенствования этой методики позволит получать более достоверные индикационные данные, чем применяемые ныне классические расчетные параметры (CIA, CIW и др.).

Основной целью работы является оценка интенсивности химического выветривания на рубеже палеоцена и эоцена в Зауралье на основе изучения соотношения $\mathrm{Ge}$ и $\mathrm{Si}$ в разновозрастных диатомитах. Вместе с тем работа содержит в себе первые результаты по индикации масштабов химического выветривая, полученные по такой методике, и общие суждения о возможности дальнейшего использования и совершенствования выбранного подхода.

\section{Объекты и методы исследования}

«Кремнистая» секция палеогенового разреза Зауралья включает в себя три стратиграфических объекта - серовскую свиту палеоцена, нижнюю и верхнюю подсвиты ирбитской свиты эоцена.

Серовская свита палеоцена $\mathrm{P}_{1} \mathrm{sr}$ сложена различными опоковидными разностями, существенно кремнистыми, глинистыми или с включениями песчаноалевритового материала. В верхней части серовской свиты также ограниченно залегают диатомиты, что обусловлено постепенными переходами толщи в диатомиты ирбитской свиты нижнего эоцена. На примере изученных разрезов можно утверждать, что макроскопически это никак не фиксируется, а только по смене диатомовых комплексов Trinacria ventriculosaSheshukovia mirabilis на Coscinodiscus UralensisHemiaulus Proteus. Мощность отложений увеличивается в восточном направлении и достигает 50-60 м.

Ирбитская свита эоцена $\mathrm{P}_{2}$ ir составляет большую часть разреза кремнистого палеогена в Зауралье и делится на две подсвиты - нижнюю и верхнюю. Нижнеирбитская подсвита сложена преимущественно диатомитами и их переходными разностями, с включениями псаммитового и алевритового материала кварц-глауконитового состава. Верхнеирбитская подсвита представлена диатомовыми и монтмориллонитбейделлитовыми глинами, глинистыми диатомитами и диатомитами. 
В рамках работы проанализированы образцы из местонахождений, которые ранее были объектами литолого-минералогических исследований и диато- мового анализа, палеоценовые диатомиты разреза Брусяна и эоценовые диатомиты Ирбитского месторождения [21] (рис. 1).

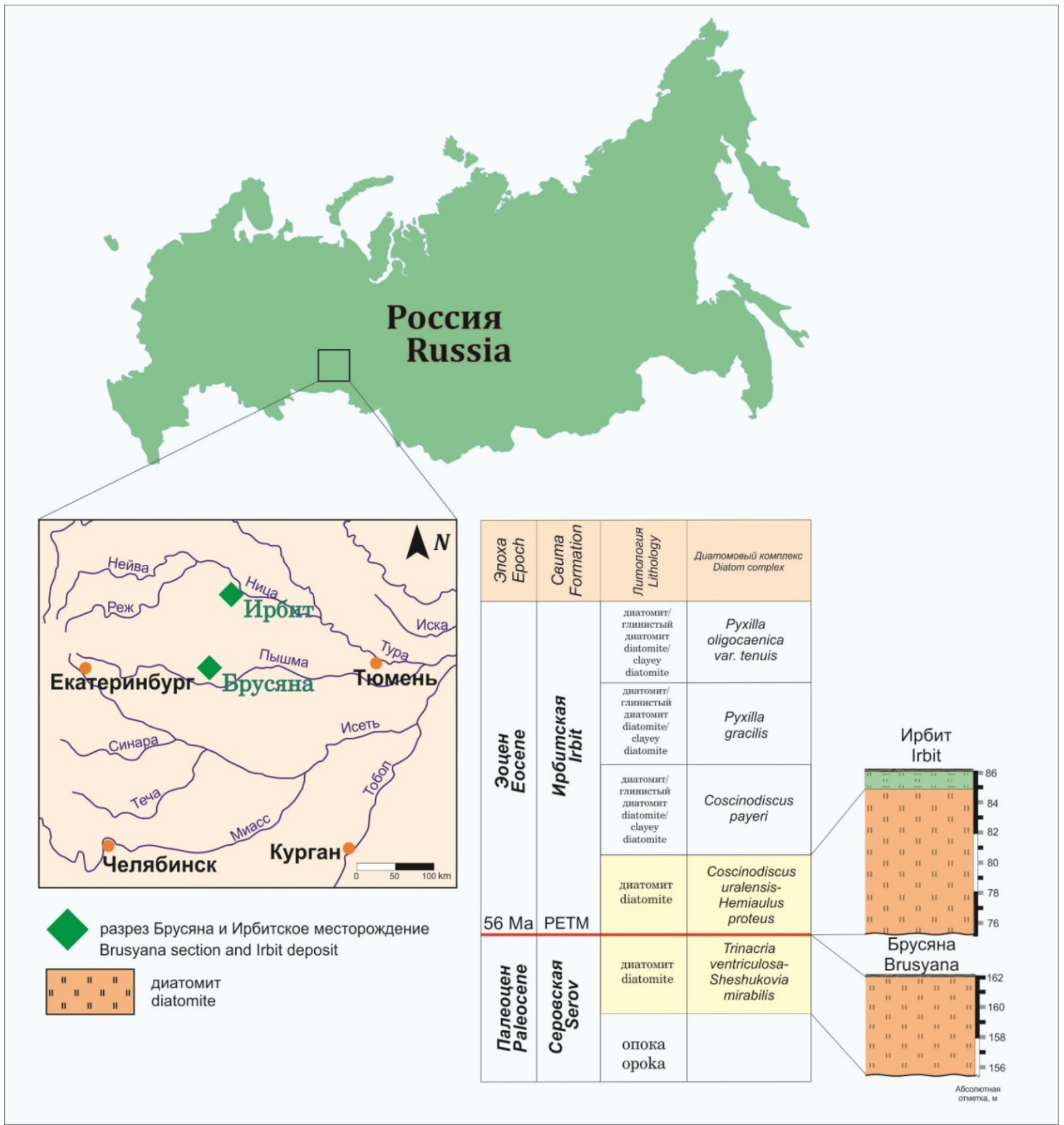

Рис. 1. Схема расположения изученных объектов

Fig. 1. Location scheme of the studied objects

Ирбитское месторождение $\left(57^{\circ} 39^{\prime} 33.16^{\prime \prime} \mathrm{N}, 63^{\circ}\right.$ 3'37.18"Е) наряду с Камышловским является одним из наиболее длительно эксплуатируемых месторождений диатомитов в Уральском регионе и расположено на юго-восточной окраине г. Ирбит (Свердловская область). Месторождение диатомита открыто по результатам комплексных геологоразведочных работ в 30-40-х гг. XX в. и в дальнейшем неоднократно становилось объектом поисково-оценочных работ для подсчета и уточнения запасов, детальных илитологогеохимических и технологических исследований [22-24].
Естественное обнажение Брусяна (56 $56^{\prime} 51.43 " \mathrm{~N}$, $\left.61^{\circ} 55^{\prime} 43.27 " Е\right)$ расположено в 3 км к северо-востоку от д. Брусяна в Свердловской области. Потенциально перспективно для поисково-оценочных и разведочных работ, но объектом такого рода изысканий обнажение и прилегающая к нему территория не являлись.

Комплекс диатомовых водорослей в диатомитах Брусяна диагностирован как Trinacria ventriculosa (b) (верхний палеоцен). Кремнескелетная флора из диатомитов Ирбитского месторождения типична для зоны Coscinodiscus payeri нижнего эоцена [20]. 


\section{Аналитические методы и подходы}

Экспериментальный блок исследований базируется на применении масс-спектрометрии с индуктивносвязанной плазмой. Для повышения надежности получаемых лабораторных данных, а также общего в рам- ках методического совершенствования выбранного подхода выполнены определения отдельно для валовых проб и для препаратов кремнистой биокластики, из которых удален глинистый материал (рис. 2).
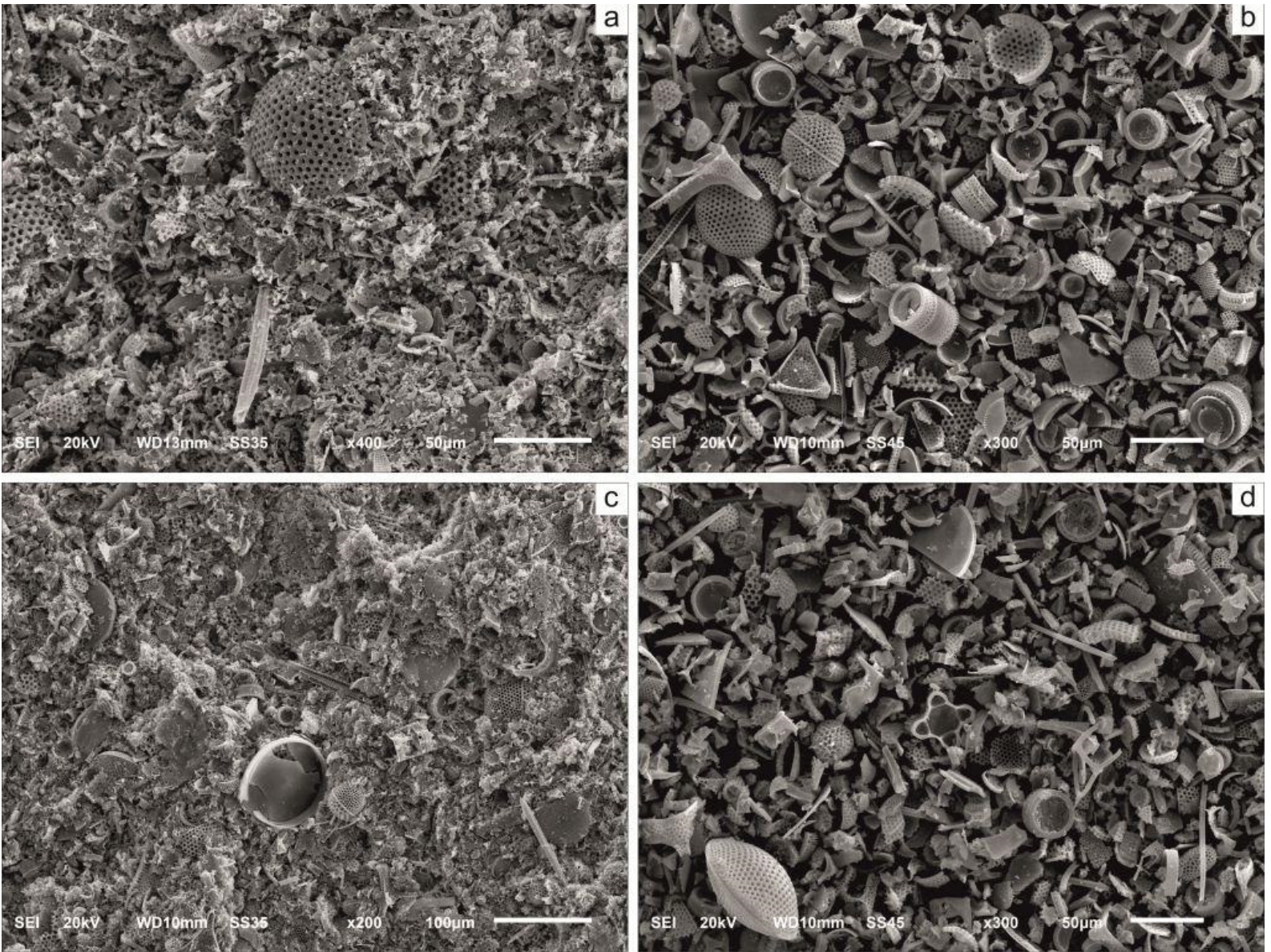

Pис. 2. Микроструктура изученных образиов: $a$, b) диатомиты разреза Брусяна, $c$, d) диатомить Ирбитского месторождения; $a, c)$ валовые образиы; $b, d)$ препараты биокластики

Fig. 2. Microscopic structure of the studied samples: $a, b)$ diatomites from the outcrop of Brusyana; $c$, d) diatomites of the Irbit deposit; $a$, c) bulk samples of diatomites; $b, d)$ preparations of bioclastics

Химическая обработка проб для получения препаратов биокластики выполнена по стандартной процедуре, принятой в лабораториях палеофлористики и микропалеонтологии ГИН РАН [11]. Изготовление препаратов кремнескелетной флоры для диатомового анализа включает в себя: 1) удаление кремнистых частиц с использованием плавиковой кислоты; 2) удаление глинистых частиц в осадке пирофосфатом натрия $\left(\mathrm{Na}_{4} \mathrm{P}_{2} \mathrm{O}_{7}\right)$, с отмыванием горячей водой в течение 2 недель; 3) разделение осадка на минеральную и органическую части в кадмиевой тяжелой жидкости $(\mathrm{CdI}+\mathrm{KI})$ с удельным весом 2,25 при помощи центрифугирования; 4) отмывание органического осадка от тяжелой жидкости дистиллированной водой; 5) сбор в пробирки, промывка и сушка мацерата с последующим добавлением глицерина. Полученные препараты кроме диатомей включают также и фрагменты иных, менее многочисленных, кремнистых организмов - радиолярий, губок, силикофлагеллат. Электронная микроско- пия для контроля качества полученных препаратов биокластики выполнена с применением растрового электронного микроскопа JEOL JSM 6510A в Тюменском индустриальном университете (г. Тюмень).

Геохимические исследования выполнены в Лаборатории изотопного и элементного анализа Института геологии и нефтегазовых технологий Казанского Федерального Университета (г. Казань). Определение содержаний оксидов проводились на рентгенофлуоресцентном волнодисперсионном спектрометре S8 Tiger (Bruker, Германия). Прибор позволяет определять элементный состав твердых, порошкообразных и жидких образцов в диапазоне от В до U в вакууме или атмосфере гелия. Прибор оснащен родиевой рентгеновской трубкой мощностью 4 кВт. Для корректных расчетов индикаторов $\mathrm{Ge} / \mathrm{Si}$ был выполнен перевод содержания $\mathrm{Si}$ в ppm через расчет в весовых процентах по соотношениям молекулярного веса окисла и его атомного веса. 
Содержания Ge получены при исследовании на масс-спектрометре с индуктивно связанной плазмой iCAP Qc (ThermoFisher Scientific, Германия). Навеска исследуемого образца массой 100 мг взвешивалась в тефлоновом автоклаве на аналитических весах с точностью 0,1 мг. В автоклав дозаторами добавлялись 2 мл концентрированной соляной кислоты $(38 \% \mathrm{HCl}$, ОСЧ), 1 мл плавиковой кислоты $(38 \% \mathrm{HCl}, \mathrm{OCЧ})$ и 1 мл концентрированной азотной кислоты $\left(68 \% \mathrm{HNO}_{3}\right.$, ОСЧ). Раствор анализировался на масс-спектрометре, предварительно откалиброванном с помощью мультиэлементных стандартов с концентрацией в диапазоне от 1 до 100 ppb каждого элемента. Конечные значения концентраций пересчитывались на исходную концентрацию с учетом пустого образца, навески и разбавления раствора.

Предел определения (ПО) $\mathrm{Ge}=0,0761$ ppm. Содержания элемента, где концентрация ниже предела определения, обычно принимают как половину передела определения.

\section{Результаты и обсуждение}

Расчетные соотношения $\mathrm{Ge} / \mathrm{Si}$ в валовых пробах диатомитов варьируются в широких пределах: для диатомитов Брусяна в интервале 1,25-14,87; для диатомитов Ирбит - 0,8-13,24 (табл. 1), подобный разброс связан со сложностью диагностики Ge и вкладом иных компонентов (в первую очередь, глин) в вариативность содержания германия.

В препаратах с отмытой биокластикой применение используемого подхода позволяет повысить качество и достоверность лабораторных данных - пиковые значения укладываются в неширокий числовой интервал (табл. 2; рис. 3).

Таблица 1. Соотношение германия и кремния в валовых образиах

Table 1. Germanium and silicon ratio in bulk samples

\begin{tabular}{|c|c|c|c|c|c|c|c|}
\hline $\begin{array}{l}\text { Шифр пробы } \\
\text { Sample code }\end{array}$ & $\mathrm{Si}, \mathrm{ppm}$ & Ge, ppm & $\mathrm{Ge} / \mathrm{Si} \times 10^{6}$ & $\begin{array}{l}\text { Шифр пробы } \\
\text { Sample code }\end{array}$ & $\mathrm{Si}, \mathrm{ppm}$ & $\mathrm{Ge}, \mathrm{ppm}$ & $\mathrm{Ge} / \mathrm{Si} \times 10^{6}$ \\
\hline \multicolumn{4}{|c|}{ Обнажение Брусяна/Brusyana section } & \multicolumn{4}{|c|}{ Ирбитское месторождение/Irbit deposit } \\
\hline B-1 & 368566,4 & 6,1490 & 11,257191 & $\mathrm{I}-1$ & 365886,1 & 3,1371 & 8,573871 \\
\hline B-2 & 382912,1 & 2,2135 & 5,780722 & $\mathrm{I}-2$ & 360333,6 & 3,4321 & 9,524678 \\
\hline B-3 & 385836,3 & 4,4080 & 11,424610 & $\mathrm{I}-3$ & 360014,3 & 2,8895 & 8,026138 \\
\hline B-4 & 364583,3 & 1,1772 & 3,228822 & I-4 & 352578,8 & 2,9654 & 8,410621 \\
\hline B-5 & 350372,5 & 0,4390 & 1,253090 & I-5 & 358696,0 & 2,7221 & 7,588886 \\
\hline B-6 & 402880,8 & 1,6956 & 4,208645 & I-6 & 346669,0 & 3,0249 & 8,725646 \\
\hline B-7 & 341909,9 & 1,0573 & 3,092329 & I-7 & 358224,4 & 2,5046 & 6,991717 \\
\hline B-8 & 375151,9 & 1,0704 & 2,853377 & I-8 & 355045,9 & 3,0704 & 8,647962 \\
\hline B-9 & 365359,0 & 1,3823 & 3,783296 & $\mathrm{I}-9$ & 352485,6 & 3,0189 & 8,564661 \\
\hline B-10 & 393773,3 & 1,2447 & 3,160970 & $\mathrm{I}-10$ & 354358,9 & 3,4414 & 9,711553 \\
\hline B-11 & 326392,3 & 1,1087 & 3,396939 & I-11 & 349314,2 & 3,8322 & 10,97064 \\
\hline B-12 & 339734,2 & 4,9459 & 14,558105 & $\mathrm{I}-12$ & 354742,2 & 2,9129 & 8,211199 \\
\hline B-13 & 332996,1 & 5,6516 & 14,869897 & $\mathrm{I}-13$ & 349796,9 & 3,2759 & 9,365237 \\
\hline B-14 & 328410,1 & 3,3197 & 10,108457 & I-14 & 353682,6 & 4,2708 & 12,07533 \\
\hline B-15 & 335073,2 & 3,6685 & 10,948269 & $\mathrm{I}-15$ & 359076,3 & 3,1197 & 8,688178 \\
\hline B-16 & 342188,9 & 2,6667 & 7,792938 & $\mathrm{I}-16$ & 351444,1 & 4,0428 & 11,50336 \\
\hline B-17 & 332054,4 & 2,2457 & 6,763034 & I-17 & 351935,8 & 3,4634 & 9,840977 \\
\hline B-18 & 335577,2 & 2,0662 & 6,157006 & I-18 & 355638,9 & 2,5091 & 7,05513 \\
\hline B-19 & 344766,3 & 2,5426 & 7,374950 & I-19 & 352866,3 & 3,6583 & 10,3673 \\
\hline B-20 & 343379,8 & 1,7707 & 5,156582 & $\mathrm{I}-20$ & 352024,6 & 2,9645 & 8,421254 \\
\hline B-21 & 391666,8 & 4,3693 & 11,155612 & $\mathrm{I}-21$ & 348134,9 & 3,5480 & 10,19159 \\
\hline B-22 & 401518,1 & 3,8366 & 9,555293 & $\mathrm{I}-22$ & 350612,3 & 2,4096 & 6,872497 \\
\hline B-23 & 390641,6 & 2,4520 & 6,276954 & $\mathrm{I}-23$ & 341921,4 & 4,5284 & 13,24388 \\
\hline B-24 & 400987,3 & 2,1800 & 5,436575 & $\mathrm{I}-24$ & 349997,4 & 3,9127 & 11,17929 \\
\hline B-25 & 387321,2 & 4,7516 & 12,267970 & $\mathrm{I}-25$ & 352968,4 & 3,7899 & 10,73712 \\
\hline B-26 & 357328,1 & 6,7973 & 13,425555 & $\mathrm{I}-26$ & 347216,3 & 0,8136 & 2,343272 \\
\hline B-27 & 359513,2 & 1,7106 & 4,758227 & $\mathrm{I}-27$ & 346736,7 & 1,2031 & 3,469664 \\
\hline \multirow[t]{13}{*}{$\mathrm{B}-28$} & 392219,0 & 5,977 & 13,199260 & $\mathrm{I}-28$ & 352518,9 & 0,9704 & 2,752744 \\
\hline & & & & $\mathrm{I}-29$ & 341584,9 & 1,0157 & 2,973567 \\
\hline & & & & $\mathrm{I}-30$ & 328429,7 & $0,0038^{*}$ & 0,115854 \\
\hline & & & & $\mathrm{I}-31$ & 342434,0 & 1,2845 & 3,751069 \\
\hline & & & & $\mathrm{I}-32$ & 346447,3 & 0,7811 & 2,254669 \\
\hline & & & & I-33 & 349990,8 & 0,4420 & 1,263031 \\
\hline & & & & $\mathrm{I}-34$ & 347861,8 & 1,1639 & 3,345946 \\
\hline & & & & $\mathrm{I}-35$ & 356401,8 & 0,2867 & 0,804493 \\
\hline & & & & I-36 & 354964,0 & 0,4928 & 1,388187 \\
\hline & & & & I-37 & 356332,2 & 1,0455 & 2,934014 \\
\hline & & & & I-38 & 351936,1 & 1,1855 & 3,368536 \\
\hline & & & & I-39 & 357739,6 & 0,9102 & 2,54419 \\
\hline & & & & $\mathrm{I}-40$ & 339869,3 & 0,5458 & 1,605929 \\
\hline
\end{tabular}

* - установленная концентрация Gе ниже ПО; значение принято как половина от ПО.

* - the established Ge concentration is lower than the limit of detection; the value is taken as half of limit of detection. 
В морской воде $\mathrm{Ge} / \mathrm{Si}\left(\mathrm{x} 10^{6}\right)$ составляет около 2,0; в современных диатомовых водорослях - чуть выше 2,0-2,2 [25]; соответственно превышения выше этого уровня можно рассматривать как обусловленные иной природой. Отличия в соотношениях $\mathrm{Ge}$ и $\mathrm{Si}$ в изученных образцах диатомитов и отмытой биокластики вполне очевидны и обусловлены различным содержанием глинистых минералов. Глинистые минералы в значительных количествах концентрируют редкие, редкоземельные и прочие элементы, включая $\mathrm{Ge}$. Внедрение Ge в глинистые минералы рассматривается как ключевой фактор фракционирования $\mathrm{Ge} / \mathrm{Si}$ в условиях выветривания [26]. В морских условиях основным концентратором германия принято считать глауконит $[27,28]$. Глаукониты и иллит-смектиты в диатомитах присутствуют в значительном количестве, и их количество в диатомитах разреза Брусяна больше, чем в диатомитах ирбитской свиты эоцена $[29,30]$. Однако пиковые значения $\mathrm{Ge} / \mathrm{Si}$ меньше, чем аналогичные для диатомитов Ирбитского месторождения. Общая индикационная картина соответствует результатам, полученным при расчете ряда классических индикационных параметров интенсивности выветривания CIA и CIW: 63-72 - для диатомитов разреза Брусяна и 88-92 - для ирбитских диатомитов $[21,31]$.

Соотношения $\mathrm{Ge} / \mathrm{Si}$ в препаратах биокластики из палеоценовых (Брусяна) и эоценовых (Ирбитское месторождение) диатомитов отличаются практически двукратно. Полученные значения стоит рассматривать как косвенное свидетельство, что интенсивность химического выветривания претерпевает на этом рубеже серьезные изменения.

Таблица 2. Соотношение германия и кремния в препаратах биокластики

Table 2. Germanium and silicon ratio in bioclactic samples

\begin{tabular}{|c|c|c|c|}
\hline $\begin{array}{l}\text { Шифр пробы } \\
\text { Sample code }\end{array}$ & $\mathrm{Si}, \mathrm{ppm}$ & $\mathrm{Ge}, \mathrm{ppm}$ & $\mathrm{Ge} / \mathrm{Si} \times 10^{6}$ \\
\hline \multicolumn{4}{|c|}{ Ирбитское месторождение/Irbit deposit } \\
\hline Ip-1 & 364093,3 & 1,1952 & 3,283 \\
\hline Ip-2 & 364756,0 & 1,2438 & 3,410 \\
\hline Ip-3 & 360322,7 & 1,3223 & 3,670 \\
\hline Ip-4 & 359095,3 & 1,2363 & 3,443 \\
\hline Ip-5 & 368405,3 & 1,3247 & 3,596 \\
\hline Ip-6 & 362814,7 & 1,2038 & 3,318 \\
\hline Ip-7 & 354064,7 & 1,2204 & 3,447 \\
\hline \multicolumn{4}{|c|}{ Обнажение Брусяна/Brusyana section } \\
\hline Bp-1 & 368993,3 & 2,3070 & 6,252 \\
\hline $\mathrm{Bp}-2$ & 368442,7 & 2,3093 & 6,268 \\
\hline Bp-3 & 359501,3 & 2,2806 & 6,344 \\
\hline Bp-4 & 364547,9 & 2,3013 & 6,313 \\
\hline Bp-5 & 344766,3 & 2,1596 & 6,264 \\
\hline Bp-6 & 382912,1 & 2,4043 & 6,279 \\
\hline Bp-7 & 361830,9 & 2,2947 & 6,342 \\
\hline
\end{tabular}

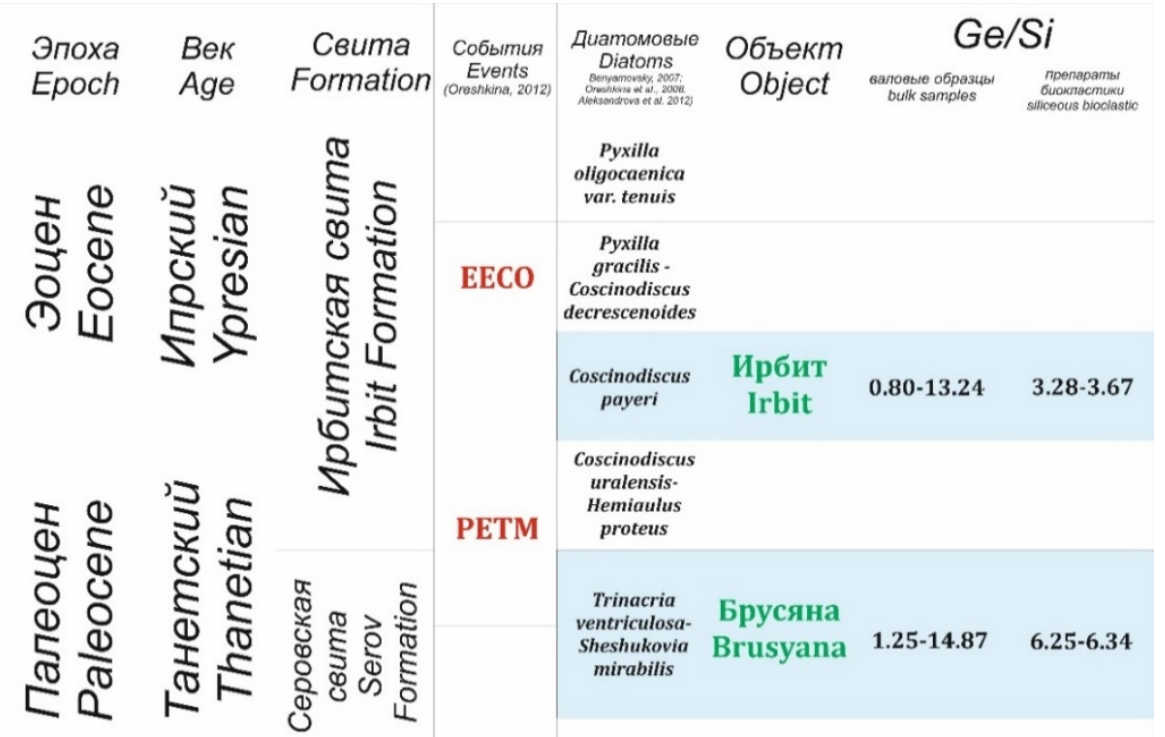

Pис. 3. Соотночения Ge/Si в валовых образиах палеоценовых и эоченовых диатомитов и полученных из них препаратов биокластики

Fig. 3. Ge/Si ratios in bulk samples of Paleocene and Eocene diatomites and bioclastic preparations obtained from them

По полученным данным пока нет оснований утверждать о том, что более высокие содержания германия (например, в диатомитах разреза Брусяна) имеют гидротермальную природу. В первую очередь, микроскопические исследования, выполненные ранее [21], не устанавливают аутигенных минеральных ассоциаций очевидно гидротермального генезиса для пород из этих местонахождений. Также стоит указать, что степень сохранности кремнескелетных форм в диатомитах разреза Брусяна выше, чем для пород Ирбитского месторождения. В условиях деятельности термальных флюидов биоморфная структура была бы подвержена существенной деструкции, что не подтверждается данными микроскопических исследова- 
ний. Таким образом можно утверждать, что эволюция пород протекала в условиях определенной удаленности от очагов разгрузки гидротерм.

Формированию палеогеновой Западно-Сибирской провинции опал-кристобалитовых пород, как абсолютно справедливо отмечает [32], способствовала большая группа факторов, действие которых было прямым либо опосредованным и которые действовали совместно и одновременно. Главными факторами биогенного кремненакопления глобального действия считают космический, топографию, рельефное разнообразие планеты и проявления внутренней динамики Земли: тектонику плит, вулканизм и магматизм [31] Огромное значение приобретал характер морской коммуникации между Арктическим океаном с океаном Тетис - Западносибирское море-пролив, которые субмеридионально пересекало Евразию и обеспечивало свободный обмен водных масс.

Весьма значимым являлся фактор климата, который на рубеже палеоцена/эоцена и в раннем-среднем эоцене был теплым и жарким и охарактеризован глобальными событиями палеоцен-эоценового термального максимума (РЕTM, 56 Ма) [7-9, 33, 34], раннеэоценового климатического оптимума (ЕECO, 53-51 Ма) и среднеэоценового климатического оптимума (MECO, 40 Мa). Повышение температуры РЕТМ сопровождалось трансформацией систем океанической и атмосферной циркуляций, оказывая во многих регионах мира существенное влияние на условия и характер седиментации, геохимический и минеральный состав осадков $[9,35,36]$, увеличение биопродуктивности неритической области моря $[33,34,36]$ подкисление морской воды $[37,38]$, развитие аноксии [39]. Результаты исследований в Западной Сибири отмечают также инвазию тепловодной флоры и фауны в морские бассейны, где ранее фиксировалось их ограниченное распространение [9, 37, 40-42].

Кремнебионтным организмам для нормальной жизнедеятельности необходимо наличие в морской/океанской воде растворенного кремнезема в достаточной концентрации. К факторам, имевшим региональное значение, относятся географическое положение и форма Западносибирского бассейна, располагавшегося почти в центре Евразии и свободно соединявшегося на севере с Арктическим океаном, на юге - с северной окраиной океана Тетис (Туранское море) и на юго-западе - с Восточно-Европейским морем через устойчивую систему проливов. Западносибирский бассейн в течение раннего-среднего палеогена испытывал циклическую смену уровней высокого и низкого стояния вод в трансгрессивнорегрессивной ритмике, связанной с общепланетарными колебаниями уровня моря в раннем палеогене [32] В бассейне существовала устойчивая система течений и противотечений, способствовавшая свободному обмену водных масс.

В глобальном биохимическом цикле кремнезема существенная роль обыкновенно принадлежит апвеллингу, общий вклад которого всегда остается велик. Вместе с тем известна критика модели апвеллинга в части объяснения причин наличия широких площадей кремненакопления на значительном удалении от береговой линии $[32,43,44]$. Определенно важное значение для Западносибирского бассейна в палеогене имел фактор континентальной эрозии, химического выветривания пород и выноса речным стоком с суши в море растворенного кремнезема и других питательных биофильных элементов. Не вызывает сомнения, что основными областями сноса являлись Уральский, Сибирский, Алтайский и Казахстанский массивы суши [21, 43-47].

Интенсификация биогенного кремненакопления в палеогене Зауралья и Западной Сибири обусловлена сложным сочетанием глобальных и региональных условий и факторов, среди которых, исходя из имеющихся данных, не представляется корректным выделить одну первопричину, которой принадлежала ключевая роль в инициации процессов кремнистой седиментации. В Зауралье и Западной Сибири для того, чтобы произошло формирование значительной по толщине страты биокремнистых пород, поступление кремнекислоты должно было быть устойчивым на протяжении всего палеоцена и раннего эоцена. К таким причинам определенно необходимо отнести гидрологические, обусловленные палеотечениями, апвеллингами и, вероятно, механизмами гравитационного вертикального перемешивания за счет плоскостной конвекции [48]. Влияние прочих факторов было не менее существенным, но, вероятно, было подвержено большей изменчивости в различные периоды времени. Так, например, полученные результаты демонстрируют, что вариативность значений германия, как уже отмечалось ранее, отражает нестабильность, неровность, волатильность его поступления в бассейн седиментации, а значит, и некий нестабильный характер факторов его поступления - континентального выветривания и, в существенно меньшей степени, гидротермализма.

Интенсивное химическое выветривание, усиление гидрологического цикла в период РЕТМ определило увеличение поставки растворенного кремнезема в морской бассейн при накоплении биокремнистых пород на территории современного Зауралья на рубеже палеоцена и эоцена. Кроме очевидных общепланетарных климатических факторов - процессов, обусловленных палеоцен-эоценовым термическим максимумом и сопряженным с ним меньшими по интенсивности термальными явлениями, на интенсификацию процессов химического выветривания существенным образом повлияли сугубо региональные условия - ослабление тектонических движений и пенепленизация суши на уральском складчатом обрамлении. Это, в свою очередь, обусловило дополнительный трансфер кремнистого вещества в форме истинных и коллоидных растворов в бассейн седиментации. Объем привноса кремнезема с суши, как можно судить, на протяжении относительного короткого периода времени стал существенно более заметен в общем балансе поставляемой в бассейн седиментации кремнекислоты. По этой же причине, т. е. из-за наличия дополнительного источника кремнекислоты, валовое содержание $\mathrm{SiO}_{2}$ в палеоценовых 
диатомитах несколько выше, чем в эоценовых [26]. В этот же момент дополнительный привнос кремнекислоты за счет процессов, инициированных РЕTМ, по всей видимости, в существенной мере уменьшился или завершился.

\section{Заключение}

В представленной работе впервые использованы содержаний $\mathrm{Ge}$ и $\mathrm{Si}$ в осадочных образованиях в России для расшифровки и реконструкции процессов в древнем седиментационном бассейне. Работа кроме практических результатов имела целью методическое совершенствование выбранного подхода и его дальнейшего дополнения, т. к. диагностика Ge в осадочных породах и любые его использования для расчета геохимических индикаторов относятся к области высокопрецизионной геохимии и еще требует дальнейшей проработки.

Содержание $\mathrm{Ge}$ в исследованных диатомитах чрезвычайно вариативно - по этой причине представляется, что диагностика $\mathrm{Ge} / \mathrm{Si}$ в валовых образцах не целесообразна, поскольку она не решает задачу спецификации и дифференциации источников привноса вещества для формирования породы, т. к. часть минеральных компонентов горной породы (в первую очередь, глинистые минералы) имеют аутигенный генезис, что отражает историю постседиментационных изменений породы.

На данном этапе индикатор $\mathrm{Ge} / \mathrm{Si}$ не обеспечивает результатов, отличных по индикационному содержанию от классических параметров химического выветривания, но намного более трудоемко в исполнении. Результаты исследования препаратов по соотношению $\mathrm{Ge}$ к Si фиксируют несколько иную тенденцию,

\section{СПИСОК ЛИТЕРАТУРЫ}

1. Кремнистые породы СССР / под ред. У.Г. Дистанова. - Казань: Татарское КИ, 1976. - 412 с

2. Смирнов П.В. Предварительные результаты ревизии минерально-сырьевой базы опал-кристобалитовых пород в среднем Зауралье // Известия Томского политехнического университета Инжиниринг георесурсов. - 2017. - Т. 328. - № 4. - С. 28-37.

3. Types, features, and resource potential of Palaeocene-Eocene siliceous rock deposits of the West Siberian Province: a review I.I. Nesterov, P.V. Smirnov, A.O. Konstantinov, H-J. Gursky // International Geology Review. - 2020. DOI $10.1080 / 00206814.2020 .1719370$

4. Akhmetiev M.A., Beniamovsky V.N. The Paleocene and Eocene in the Russian part of West Eurasia // Stratigraphy and Geological correlation. - 2006. - V. 14. - № 1. - P. 49-72.

5. Open and semi-closed Paleogene marine systems in Northeastern Peri-Tethys: stable and transitional biostratigraphic, paleogeographic and paleoclimatological aspects M.A. Akhmetiev, N.I. Zaporozhets, V.N. Beniamovsky, G.N. Aleksandrova, A.I. Iakovleva, T.V. Oreshkina // Austrian Journal of Earth Sciences. - 2012. - V. 105. - № 1. - P. 50-67.

6. Смирнов П.В., Константинов А.О. Биогенное кремненакопление в Западно-Сибирском морском бассейне в палеоценеэоцене: факторы и стадии // Литосфера. - 2017. - Т. 17. - № 4. C. 26-47. DOI: 10.24930/1681-9004-2017-4-026-047

7. Thomas E., Shackleton N. J. The Paleocene-Eocene benthic foraminiferal extinction and stable isotope anomalies // Geological Society Special Publications. - 1996. - V. 101. - № 1. - P. 401-441 DOI: doi.org/10.1144/GSL.SP.1996.101.01.20

8. A transient rise in tropical sea surface temperature during the PaleoceneEocene Thermal Maximum / J.C. Zachos, M.W. Wara, S. Bohaty, чем та, что определяется по данным CIA или CIW значения $\mathrm{Ge} / \mathrm{Si}$ указывают, что объемы химического выветривания в палеоцене превышали таковые в раннеэоценовое время. Такие данные согласуются с полученными ранее сведениями о более высоком содержании кремнезема в палеоценовых диатомитах, которые текущие генетические модели четко не объясняют.

Полученные результаты являются предварительными, но фиксируют общую тенденцию к наращиванию на границе палеоцена-эоцена объема кремнезема получаемого в результате эрозии и химического выветривания пород на прилегающей суше.

На основании проведенных исследований можно сделать ряд предположений и обобщений:

- место общей рамки в биогенном кремненакоплении принадлежало гидродинамическим причинам: свободному обмену водных масс и открытости морского Западно-Сибирского бассейна, системе устойчивых палеотечений, механизмам гравитационного вертикального перемешивания за счет плоскостной конвекции, апвеллингам; влияние других факторов, по всей видимости, было не менее значимым, но объемы поступления кремнезема от них были подвержены большей волатильности;

- PETM в регионе не стал инициатором кардинальных трансформаций общего характера осадконакопления, однако дополнительный привнос кремния определил более высокое содержание кремнезема в палеоценовых диатомитах, в сравнении с эоценовыми.

Исследование выполнено при финансовой поддержке РФФИ в рамках научных проектов 18-35-00034 и 19-35-60004.

M.L. Delaney, M.R. Petrizzo, A. Brill, I. Premoli-Silva // Science. - 2003. V. 302 (5650). - P. 1551-1554. DOI: 10.1126/science.1090110

9. Paleocene-Eocene warming and biotic response in the epicontinental West Siberian Sea / J. Frieling, A.I. Iakovleva, G.-J. Reichart, G.N. Aleksandrova, Z.N. Gnibidenko, S. Schouten, A. Sluijs // Geology. - 2014. - V. 42. - 9. - P. 767-770. URL: https://doi.org/10.1130/G35724.1 (дата обращения 01.02.2020).

10. Казаринов В.П., Казанский Ю.П. Кремнистые породы // Выветривание и литогенез. - М.: Недра, 1969. - С. 384-400.

11. Диатомеи и диноцисты в интервале позднего палеоцена - раннего эоцена в биокремнистых фациях среднего Зауралья / Г.Н. Александрова, Т.В. Орешкина, А.И. Яковлева, Э.П. Радионова // Стратиграфия. Геологическая корреляция. - 2012. - Т. 20. - № 4. - С. 68-94.

12. Bernstein L.R. Germanium geochemistry and mineralogy // Geochimica et Cosmochimica Acta. - 1985. - V. 49. - P. 2409-2422. DOI: doi.org/10.1016/0016-7037(85)90241-8

13. Pokrovski G.S., Schott J. Thermodynamic properties of aqueous $\mathrm{Ge}(\mathrm{IV})$ hydroxide complexes from 25 to 350 degrees C: implications for the behavior of germanium and the $\mathrm{Ge} / \mathrm{Si}$ ratio in hydrothermal fluids // Geochimica et Cosmochimica Acta. - 1998. № 62. - P. 1631-1642. DOI: 10.1016/s0016-7037(98)00081-7

14. Molybdenum isotope signatures in continental margin marine sediments / V. Siebert, J. McManus, A. Bice, R. Poulson, W.M. Berelson // Earth and Planetary Science Letters. - 2006. № 241. - P. 723-733. DOI: 10.1016/j.epsl.2005.11.010

15. Froelich P.N., Andreae M.O. The marine geochemistry of germanium: ekasilicon // Science. - 1981. - V. 13. - P. 205-207. DOI: $10.1126 /$ science. 213.4504 .205

16. The geochemistry of inorganic germanium in natural waters / P.N. Froelich, G.A. Hambrick, M.O. Andreae, R.A. Mortlock, J.M. Edmond // Journal of Geophysical Research: Oceans. 1985. - V. 90. - P. 1133-1141. doi.org/10.1029/JC090iC01p01133 
17. Silica and germanium in Pacific Ocean hydrothermal events and plumes R.A. Mortlock, P.N. Froelich, R.A. Feely, G.J. Massoth, D.A. Butterfield, J.E. Lupton // Earth and Planetary Science Letters. - 1983. - V. 119. P. 365-378. DOI: doi.org/10.1016/0012-821X(93)90144-X

18. Mortlock R.A., Froelich P.N. Continental weathering of germanium $-\mathrm{Ge} / \mathrm{Si}$ in the global river discharge. // Geochimica et Cosmochimica Acta. - 1987. - V. 51. - P. 2075-2082. DOI: 10.1016/0016-7037(87)90257-2

19. Shemesh A., Mortlock R.A., Froelich P.N. Late Cenozoic Ge/Si record of marine biogenic opal: implications for variation of riverine fluxes to the ocean // Paleoceanography. - 1989. - V. 3. P. 221-234. DOI: doi.org/10.1029/PA004i003p00221

20. Transfer of germanium to marine sediments: insights from its accumulation in radiolarites and authigenic capture under reducing conditions. Some examples through geological ages N. Tribovillard, V. Bout-Roumazeilles, A. Riboulleau, F. Baudin, T. Danelian, L. Riquier // Chemical Geology. - 2011. - V. 282. P. 120-130. DOI: 10.1016/j.chemgeo.2011.01.015

21. Smirnov P.V., Konstantinov A.O., Gursky H-J. Petrology and industrial application of main diatomite deposits in the Transuralian region (Russian Federation) // Environmental Earth Sciences. 2017. - V. 76. - P. 682[PS1]. DOI: doi.org/10.1007/s12665-0177037-3

22. Ирбитские диатомиты как потенциальное сырье для синтеза растворимых силикатов / Л.Н. Нажарова, Т.С. Гнусина, А.М. Губайдуллина, Е.Н. Филиппович // Вестник Казанского технологического университета. - 2013. - № 21. - С. 49-51.

23. Смирнов П.В. Результаты комплексных исследований вещественного состава диатомитов Ирбитского месторождения // Известия Томского Политехнического Университета. Инжиниринг георесурсов. - 2016. - Т. 327. - № 6. - С. 93-104.

24. Модифицированные сорбенты на основе диатомитов / Нгуен Вьет Кыонг, П.С. Короткова, Э.Н. Ханмамедова, Л.С. Григорьева // Вестник МГСУ. - 2019. - Т. 14. - №. 7. - С. 862-869. DOI: $10.22227 / 1997-0935.2019 .7 .862-869$

25. Germanium incorporation into sponge spicules: development of a proxy for reconstructing inorganic germanium and silicon concentrations in seawater / M.J. Ellwood, M. Kelly, W.A. Maher, P. de Deckker // Earth and Planetary Science Letters. - 2006. V. 243. - P. 749-759.

26. Tribovillard N. The Ge/Si ratio as a tool to recognize biogenic silica in chert // Comptes Rendus Geoscience. - 2013. - № 345. P. 160-165. DOI: 10.1016/j.crte.2013.02.005

27. Kurtz A.C., Derry L.A., Chadwick O.A. Germanium-silicon fractionation in the weathering environment // Geochimica et Cosmochimica Acta. - 2002. - V. 66. - P. 1525-1537. DOI: 10.1016/j.gca.2009.11.027

28. Rouxel O., Galy A., Elderfield H. Germanium isotopic variations in igneous rocks and marine sediments // Geochimica et Cosmochimica Acta. - 2006. - V. 70. - P. 3387-3400. DOI: 10.1016/j.gca.2006.04.025

29. Смирнов П.В., Константинов А.О. Сравнительные исследования эоценовых и палеоценовых диатомитов Зауралья (на примере Камышловского месторождения и разреза Брусяна) // Известия Томского политехнического университета. Инжиниринг георесурсов. - 2016. - Т. 327. - № 11. - С. 96-104.

30. Смирнов П.В., Константинов А.О. Диатомовые глины Шадринского месторождения (Курганская область) // Георесурсы. 2016. - T. 18. - № 3. - C. 240-244.

31. Variability in distribution of major and trace elements in Lower Eocene siliceous sections of Transuralian region (Russia) P.V. Smirnov, A.O. Konstantinov, G.A. Batalin, B.I. Gareev // Acta Geochimica. - 2019. - V. 38. - № 2. - P. 262-276.

32. Амон Э.О. Факторы и условия накопления биогенных силицитов в палеогеновом бассейне Западной Сибири // Бюллетень Московского общества испытателей природы. Отдел геологический. - 2018. - Т. 93. - № 4. - С. 51-67.

33. Kennett J.P., Stott L.D. Abrupt deep-sea warming, paleoceanographic changes and benthic extinctions at the end of the Paleocene // Nature. - 1991. - V. 353. - P. 225-229.
34. Stassen P., Thomas E., Speijer R.P. Paleocene-Eocene Thermal Maximum environmental change in the New Jersey Coastal Plain: Benthic foraminiferal biotic events // Marine Micropaleontology. 2015. - V. 115. - P. 1-23. doi.org/10.1016/j.marmicro.2014.12.001

35. McInerney F.A., Wing S.L. The Paleocene-Eocene Thermal Maximum: A perturbation of carbon cycle, climate, and biosphere with implications for the future // Annual Review of Earth and Planetary Sciences. - 2011. - V. 39. - №1. - P. 489-516. DOI: doi.org/10.1146/annurev-earth-040610-133431

36. Environmental dynamics during the Paleocene-Eocene thermal maximum (PETM) in the northeastern Peri-Tethys revealed by high-resolution micropalaeontological and geochemical studies of a Caucasian key section / E. Shcherbinina, Y. Gavrilov, A. Iakovleva, B. Pokrovsky, O. Golovanova, G. Aleksandrova // Palaeogeography, Palaeoclimatology, Palaeoecology. - 2016. V. 456. - P. 60-81. DOI: doi.org/10.1016/j.palaeo.2016.05.006

37. Rapid and sustained surface ocean acidification during the Paleocene-Eocene Thermal Maximum / D.E. Penman, B. Honisch, R.E. Zeebe, E. Thomas, J.C. Zachos // Paleoceanography. - 2014. V. 29. - № 5. - P. 357-369. DOI: doi.org/10.1002/2014PA002621

38. Capturing the global signature of surface ocean acidification during the Paleocene-Eocene Thermal Maximum / T.L. Babila, D.E. Penman, B. Hönisch, D.C. Kelly, T.J. Bralower, Y. Rosenthal, J.C. Zachos // Philosophical Transactions of the Royal Society A. 2018. - V. 376. - 20170072. DOI: 10.1098/rsta.2017.0072.

39. Termination of global warmth at the Palaeocene/Eocene boundary through productivity feedback / S. Bains, R.D Norris., R.M. Corfield, K.L. Faul // Nature. - 2000. - V. 407. -№ 6801. P. 171-174. DOI: doi.org/10.1038/35025035.

40. The spread of marine anoxia on the northern Tethys margin during the Paleocene-Eocene Thermal Maximum / A.J. Dickson, R.L. Rees-Owen, C. Marz, A.L. Coe, A.S. Cohen, R. Pancost, E. Shcherbinina // Paleoceanography. - 2014. - V. 29. - № 6. P. 471-488. DOI: doi.org/10.1002/2014PA002629

41. Oreshkina T.V. Evidence of Late Paleocene-Early Eocene hyperthermal events in biosiliceous sediments of western Siberia and adjacent areas // Austrian Journal of Earth Sciences. - 2012. V. $105 .-$ P. $145-153$.

42. Oreshkina T.V., Oberhänsli H. Diatom turnover in the Early Paleogene diatomite of the Sengiley section, middle Povolzhie, Russia: a response to the initial Eocene Thermal Maximum? // Geological Society of America Special Papers. - 2003. - V. 369. P. $169-179$. DOI: $10.1130 / 0-8137-2369-8.169$

43. Цеховский Ю.Г. Седиментогенез и геодинамика в пограничную мел-палеогеновую эпоху пенепленизации континентов. Сообщение 1. Центральная и восточная Евразия // Литосфера. 2015. - № 1. - C. 5-23.

44. Цеховский Ю.Г. Седиментогенез и геодинамика в пограничную мел-палеогеновую эпоху пенепленизации континентов. Сообщение 2. платформы и подвижные пояса // Литосфера. 2015. - № 2. - C. 5-16.

45. Шацкий С.Б. Основные вопросы стратиграфии и палеогеографии палеогена Сибири // Палеоген и неоген Сибири. - Новосибирск: Наука, 1978. - С. 3-32.

46. Цеховский Ю.Г. Участие вулканизма и гидротерм в платформенном осадконакоплении пограничной мел-палеогеновой эпохи деструктивного тектогенеза в Центральной Евразии. Статья 1. Палеогеография, продукты вулканизма и гидротермальной деятельности // Бюллетень Московского общества испытателей природы. Отдел геологический. - 2017. - Т. 92. № 4. - С. 34-48.

47. Цеховский Ю.Г. Участие вулканизма и гидротерм в платформенном осадконакоплении пограничной мел-палеогеновой эпохи деструктивного тектогенеза в Центральной Евразии. Статья 2. особенности платформенного осадконакопления // Бюллетень Московского общества испытателей природы. Отдел геологический. - 2017. - Т. 92. - № 6. - С. 3-13.

48. Безруков Ю.Ф. Океанология. Часть І. Физические явления и процессы в океане. - Симферополь: Таврический нац. ун-т им. В.И. Вернадского, 2006. -159 с. 


\section{Информация об авторах}

Смирнов П.В., кандидат геолого-минералогических наук, научный сотрудник Тюменского государственного университета; научный сотрудник Тюменского индустриального университета.

Баталин Г.A., научный сотрудник Казанского федерального университета.

Гареев Б.И., научный сотрудник Казанского федерального университета.

Tрифонов A.A., научный сотрудник Казанского федерального университета. 
UDC 552.52; 552.08; 553.611

\title{
Ge-Si RATIO FOR ASSESSING THE CHEMICAL WEATHERING INTENSITY AT THE PALEOCENE-EOCENE BOUNDARY IN ANCIENT TRANSURALIAN BASIN
}

Pavel V. Smirnov1,2, geolog.08@mail.ru

Georgii A. Batalin', g@batalin.com

Bulat I. Gareev, bulat@gareev.net

\author{
Artem A. Trifonov ${ }^{3}$, \\ ar3tyrt5y@gmail.com \\ 1 University of Tyumen, \\ 6 , Volodarsky street, Tyumen, 625003, Russia. \\ 2 Tyumen Industrial University, \\ 38 , Volodarsky street, Tyumen, 625000 , Russia. \\ 3 Kazan Federal University, \\ 4/5, Kremlevskaya street, Kazan, 420008, Russia.
}

Relevance. Diatomites and their transitional differences formed in the Paleocene-Eocene marine basin are one of the most widespread in the near-surface occurrence of sedimentary rocks in the vast territory of the Trans-Urals. At the same time, with regard to the genetic aspects of such rocks, the discussion on the fundamental sources of silica for formation remains still relevant. An urgent task is to analyze the role of each of two factors in the origin of rocks - continental weathering and upwelling activities. The ratio of Ge to Si can potentially be considered as a tool for deciphering the source of silica in biogenic siliceous rocks, since germanium is delivered to the rock by incorporation into biogenic opal; Ge introduction into the rock from other sources during the diagenesis is not significant, which makes the results indicatively valuable.

The main aim is estimation of the chemical weathering intensity at the boundary of the Paleocene and Eocene in the Trans-Urals based on the study of the ratio of $\mathrm{Ge}$ and $\mathrm{Si}$ in diatomites of different ages.

The methods: field studies, $X$-ray fluorescence analysis, inductively coupled plasma mass spectrometry, scanning electron microscopy.

The results. The paper contains the first results of estimation of chemical weathering intensity at the boundary of the Paleocene and Eocene in the Trans-Urals by analyzing the ratios of germanium and silicon in bulk diatomite samples and bioclastic preparations, where clay material was removed. The Ge/Si ratios in bioclastic preparations from the Paleocene (Brusyana section) and Eocene (Irbit deposit) differ almost twofold. The obtained values should be considered as mark that the intensity of chemical weathering undergoes serious changes at this boundary: intensive chemical weathering, strengthening of the hydrological cycle during the PETM period determined an increase in the supply of dissolved silica to the marine basin during the accumulation of biosiliceous rocks in the territory of modern TransUrals. The weakening of tectonic movements and land peneplenisation within the East Ural contributed to the weathering intensification. This provided an additional transfer of siliceous matter in the form of true and colloidal solutions to the sedimentation basin for the biosiliceous rocks accumulation. The amount of silica influx from land over a relatively short period of time became more noticeable in the overall balance of silica supplied to the sedimentation basin. For the same reason, i. e. the presence of an additional source of silicic acid, the gross $\mathrm{SiO}_{2}$ content in the Paleocene diatomites is slightly higher than in the Eocene.

\section{Key words:}

Diatomite, Paleocene, Eocene, Trans-Urals, Western Siberia, PETM, germanium, silicon.

The reported study was funded by the RFBR according to the research projects 18-35-00034 and 19-35-60004.

\section{REFERENCES}

1. Kremnistye porody SSSR [Siliceous rocks of the USSR]. Ed. by U.G. Distanov. Kazan, Tatar Publ., 1976. 412 p.

2. Smirnov P.V. Preliminary results of revision of mineral-raw material base of opal-cristobalite rocks in Middle Trans-Urals. Bulletin of the Tomsk Polytechnic University. Geo Assets Engineering, 2017, vol. 328, no. 4, pp. 28-37. In Rus.

3. Nesterov I.I., Smirnov P.V., Konstantinov A.O., Gursky H-J. Types, features, and resource potential of Palaeocene-Eocene siliceous rock deposits of the West Siberian Province: a review. International Geology Review, 2020. DOI: $10.1080 / 00206814.2020 .1719370$
4. Akhmetiev M.A., Beniamovsky V.N. The Paleocene and Eocene in the Russian part of West Eurasia. Stratigraphy and Geological correlation, 2006, vol. 14, no. 1, pp. 49-72.

5. Akhmetiev M.A., Zaporozhets N.I., Beniamovsky V.N., Aleksandrova G.N., Iakovleva A.I., Oreshkina T.V. Open and semi-closed Paleogene marine systems in Northeastern PeriTethys: stable and transitional biostratigraphic, paleogeographic and paleoclimatological aspects. Austrian Journal of Earth Sciences, 2012, vol. 105, no. 1, pp. 50-67.

6. Smirnov P.V., Konstantinov A.O. Biogenic siliceous accumulation in Early Paleogene marine basins of Western Siberia. Litosfera, 2017 , vol. 17 , no. 4, pp. 26-47. In Rus. DOI: 10.24930/16819004-2017-4-026-047 
7. Thomas E., Shackleton N. J. The Paleocene-Eocene benthic foraminiferal extinction and stable isotope anomalies. Geological Society Special Publications, 1996, vol. 101, no. 1, pp. 401-441. DOI: doi.org/10.1144/GSL.SP.1996.101.01.20

8. Zachos J.C., Wara M.W., Bohaty S., Delaney M.L., Petrizzo M.R., Brill A., Premoli-Silva I. A transient rise in tropical sea surface temperature during the Paleocene-Eocene Thermal Maximum Science, 2003, vol. 302, no. 5650, pp. 1551-1554. DOI: $10.1126 /$ science. 1090110

9. Frieling J., Iakovleva A.I., Reichart G.-J., Aleksandrova G.N., Gnibidenko Z.N., Schouten S., Sluijs A. Paleocene-Eocene warming and biotic response in the epicontinental West Siberian Sea. Geology, 2014, vol. 42, no. 9, pp. 767-770. DOI: doi.org/10.1130/G35724.1

10. Kazarinov V.P., Kazanskii Yu.P. Kremnistye porody. Vyvetrivanie $i$ litogenez [Siliceous rocks. Weathering and Lithogenesis]. Moscow, Nedra Publ., 1969. 456 p.

11. Aleksandrova G.N., Oreshkina T.V., Iakovleva A.I., Radionova E.P. Late Paleocene - Early Eocene diatoms and dinocysts from biosiliceous facies of the middle Trans-Urals region. Stratigraphy and Geological Correlation, 2012, vol. 20, no. 4, pp. 380-404.

12. Bernstein L.R. Germanium geochemistry and mineralogy. Geochimica et Cosmochimica Acta, 1985, vol. 49, pp. 2409-2422. DOI: doi.org/10.1016/0016-7037(85)90241-8

13. Pokrovski G.S., Schott J. Thermodynamic properties of aqueous $\mathrm{Ge}(\mathrm{IV})$ hydroxide complexes from 25 to 350 degrees $\mathrm{C}$ implications for the behavior of germanium and the $\mathrm{Ge} / \mathrm{Si}$ ratio in hydrothermal fluids. Geochimica et Cosmochimica Acta, 1998 , no. 62, pp. 1631-1642. DOI: 10.1016/s0016-7037(98)00081-7

14. Siebert V., McManus J., Bice A., Poulson R., Berelson W.M. Molybdenum isotope signatures in continental margin marine sediments. Earth and Planetary Science Letters, 2006, no. 241, pp. 723-733. DOI:10.1016/j.eps1.2005.11.010

15. Froelich P.N., Andreae M.O. The marine geochemistry of germanium: ekasilicon. Science, 1981, vol. 13, pp. 205-207. DOI: 10.1126/science.213.4504.205

16. Froelich N., Hambrick G.A., Andreae M.O., Mortlock R.A., Edmond J.M. The geochemistry of inorganic germanium in natural waters. Journal of Geophysical Research: Oceans, 1985, vol. 90, pp. 1133-1141. DOI: doi.org/10.1029/JC090iC01p01133

17. Mortlock R.A., Froelich P.N., Feely R.A., Massoth G.J., Butterfield D.A., Lupton J.E. Silica and germanium in Pacific Ocean hydrothermal events and plumes. Earth and Planetary Science Letters, 1983, vol. 119, pp. 365-378. DOI: doi.org/10.1016/0012-821X(93)90144-X

18. Mortlock R.A., Froelich P.N. Continental weathering of germanium - $\mathrm{Ge} / \mathrm{Si}$ in the global river discharge. Geochimica et Cosmochimica Acta, 1987, vol. 51, pp. 2075-2082. DOI: 10.1016/0016-7037(87)90257-2

19. Shemesh A., Mortlock R.A., Froelich P.N. Late Cenozoic Ge/Si record of marine biogenic opal: implications for variation of riverine fluxes to the ocean. Paleoceanography, 1989, vol. 3, pp. 221234. DOI: doi.org/10.1029/PA004i003p00221

20. Tribovillard N., Bout-Roumazeilles V., Riboulleau A., Baudin F., Danelian T., Riquier L. Transfer of germanium to marine sediments: insights from its accumulation in radiolarites and authigenic capture under reducing conditions. Some examples through geological ages. Chemical Geology, 2011, vol. 282, pp. 120-130. DOI: 10.1016/j.chemgeo.2011.01.015

21. Smirnov P.V., Konstantinov A.O., Gursky H-J. Petrology and industrial application of main diatomite deposits in the Transuralian region (Russian Federation). Environmental Earth Sciences, 2017, vol. 76, pp. 682. DOI: doi.org/10.1007/s12665017-7037-3

22. Ellwood M.J., Kelly M., Maher W.A., De Deckker P. Germanium incorporation into sponge spicules: development of a proxy for reconstructing inorganic germanium and silicon concentrations in seawater. Earth and Planetary Science Letters, 2006, vol. 243, pp. 749-759.

23. Nazharova L.N., Gnusina T.S., Gubaydullina A.M., Filippovich E.N Irbitsk diatomite as a potential raw material for synthesis of soluble silicates. Vestnik Kazanskogo tekhnologicheskogo universiteta, 2013, no. 21, pp. 49-51. In Rus.

24. Smirnov P.V. Results of comprehensive studies of diatomite material composition from Irbit deposit. Bulletin of the Tomsk
Polytechnic University. Geo Assets Engineering, 2016, vol. 327, no. 6, pp. 93-104. In Rus.

25. Nguyen Viet Cong, Korotkova P.S., Khanmamedova E.N., Grigoryeva L.S. Modified sorbents based on diatomites. Vestnik MGSU, 2019, vol. 14, no. 7, pp. 862-869. DOI: 10.22227/19970935.2019.7.862-869 In Rus.

26. Tribovillard $\mathrm{N}$. The $\mathrm{Ge} / \mathrm{Si}$ ratio as a tool to recognize biogenic silica in chert. Comptes Rendus Geoscience, 2013, no. 345, pp. 160-165. DOI: 10.1016/j.crte.2013.02.005

27. Kurtz A.C., Derry L.A., Chadwick O.A. Germanium-silicon fractionation in the weathering environment. Geochimica et Cosmochimica Acta, 2002, vol. 66, pp. 1525-1537. DOI: 10.1016/j.gca.2009.11.027

28. Rouxel O., Galy A., Elderfield H. Germanium isotopic variations in igneous rocks and marine sediments. Geochimica et Cosmochimica Acta, 2006, vol. 70, pp. 3387-3400. DOI: 10.1016/j.gca.2006.04.025

29. Smirnov P.V., Konstantinov A.O. Comparative studies of Eocene and Paleocene diatomite from Trans-Urals (on the example of Kamyshlov deposit and section Brusyana). Bulletin of the Tomsk Polytechnic University. Geo Assets Engineering, 2016, vol. 327, no. 11, pp. 96-104. In Rus.

30. Smirnov P.V., Konstantinov A.O. Diatomaceous Clay of Shadrinsky deposit (Kurgan Region). Georesources, 2016, vol. 18, no. 3, pp. 240-244. DOI: 10.18599/grs.18.3.16 In Rus.

31. Smirnov P.V., Konstantinov A.O., Batalin G.A., Gareev B.I. Variability in distribution of major and trace elements in Lower Eocene siliceous sections of Transuralian region (Russia). Acta Geochimica, vol. 38, no. 2, pp. 262-276.

32. Amon E.O. Faktory i usloviya nakopleniya biogennykh silitsitov v paleogenovom basseyne Zapadnoy Sibiri [Factors and conditions for the accumulation of biogenic silicites in the Paleogene Basin of Western Siberia]. Bulletin of Moscow Society of Naturalists. Geological series, 2018, vol. 93, no. 4, pp. 51-67.

33. Kennett J.P., Stott L.D. Abrupt deep-sea warming, paleoceanographic changes and benthic extinctions at the end of the Paleocene. Nature, 1991, vol. 353, pp. 225-229.

34. Stassen P., Thomas E., Speijer R.P. Paleocene-Eocene Thermal Maximum environmental change in the New Jersey Coastal Plain: Benthic foraminiferal biotic events. Marine Micropaleontology, 2015, vol. 115, pp.1-23. DOI: doi.org/10.1016/j.marmicro.2014.12.001

35. McInerney F. A., Wing S.L. The Paleocene-Eocene Thermal Maximum: a perturbation of carbon cycle, climate, and biosphere with implications for the future. Annual Review of Earth and Planetary Sciences, 2011, vol. 39, no. 1, pp. 489-516. DOI: doi.org/10.1146/annurev-earth-040610-133431

36. Shcherbinina E., Gavrilov Y., Iakovleva A., Pokrovsky B., Golovanova O., Aleksandrova, G. Environmental dynamics during the Paleocene-Eocene thermal maximum (PETM) in the northeastern Peri-Tethys revealed by high-resolution micropalaeontological and geochemical studies of a Caucasian key section. Palaeogeography, Palaeoclimatology, Palaeoecology, 2016, vol. 456, pp. 60-81. DOI: doi.org/10.1016/j.palaeo.2016.05.006

37. Penman D. E., Honisch B., Zeebe R.E., Thomas E., Zachos J.C. Rapid and sustained surface ocean acidification during the Paleocene-Eocene Thermal Maximum. Paleoceanography, 2014, vol. 29, no. 5, pp. 357-369. DOI: doi.org/10.1002/2014PA002621

38. Babila T.L., Penman D.E., Hönisch B., Kelly D.C., Bralower T.J., Rosenthal Y., Zachos J.C. Capturing the global signature of surface ocean acidification during the Palaeocene-Eocene Thermal Maximum. Philosophical Transactions of the Royal Society A, 2018, vol. 376. 20170072. DOI: 10.1098/rsta.2017.0072.

39. Bains S., Norris R.D., Corfield R.M., Faul K.L. Termination of global warmth at the Palaeocene/Eocene boundary through productivity feedback. Nature, 2000 , vol. 407 , no. 6801 , pp. $171-$ 174. DOI: doi.org/10.1038/35025035.

40. Dickson A.J., Rees-Owen R.L., Marz C., Coe A.L., Cohen A.S., Pancost R., Shcherbinina E. The spread of marine anoxia on the northern Tethys margin during the Paleocene-Eocene Thermal Maximum. Paleoceanography, 2014, vol. 29, no. 6, pp. 471-488. DOI: doi.org/10.1002/2014PA002629

41. Oreshkina T.V. Evidence of Late Paleocene-Early Eocene hyperthermal events in biosiliceous sediments of western Siberia 
and adjacent areas. Austrian Journal of Earth Sciences, 2012, vol. 105 , pp. $145-153$

42. Oreshkina T.V., Oberhänsli H. Diatom turnover in the Early Paleogene diatomite of the Sengiley section, middle Povolzhie, Russia: a response to the initial Eocene Thermal Maximum? Geological Society of America Special Papers, 2003, vol. 369, pp. 169-179. DOI: $10.1130 / 0-8137-2369-8.169$

43. Tsekhovsky Yu.G. Sedimentogenesis and geodynamics in the Cretaceous-Paleogene boundary at the epoch of continental peneplanation. Article 1. Central and Eastern Eurasia. Litosfera, 2015, no.1, pp. 5-23. In Rus.

44. Tsekhovsky Yu.G. Sedimentogenesis and geodynamics in the Cretaceous-Paleogene boundary at the epoch of continental peneplanation. Article 2. Platforms and mobile belts. Litosfera, 2015, no. 2, pp. 5-16. In Rus.

45. Shatskii S.B. Osnovnye voprosy stratigrafii i paleogeografii paleogena Sibiri [The main issues of stratigraphy and paleogeography of the Paleogene of Siberia]. Paleogen $i$ neogen Sibiri. Novosibirsk, Nauka Publ., 1978. pp. 3-32.
46. Tsekhovsky Yu.G. The participation of volcanism and hydrothermal in platform sedimentation of the boundary Cretaceous-Paleogene era of destructive tectogenesis in Central Eurasia. Article 1. Paleogeography, products of volcanism and hydrothermal activity. Bulletin of Moscow Society of Naturalists. Geological series, 2017, vol. 92, no. 4, pp. 34-48. In Rus.

47. Tsekhovsky Yu.G. The participation of volcanism and hydrothermal in platform sedimentation of the boundary Cretaceous-Paleogene era of destructive tectogenesis in Central Eurasia. Article 2. features of platform sedimentation. Bulletin of Moscow Society of Naturalists. Geological series, 2017, vol. 92, no. 6, pp. 3-13. In Rus.

48. Bezrukov Y.F. Okeanologiva. Chast I. Fizicheskie yavleniya $i$ protsessy $v$ okeane [Oceanology P. I. Physical phenomena and processes in the ocean]. Simferopol, Taurian National University named after V.I. Vernadsky, 2006. 159 p.

Received: 12 March 2020.

\section{Information about the authors}

Pavel V. Smirnov, Cand. Sc., scientific researcher, Tyumen Industrial University; scientific researcher, Technische Universität Clausthal.

Georgii A. Batalin, scientific researcher, Kazan Federal University.

Bulat I. Gareev, scientific researcher, Kazan Federal University.

Artem A. Trifonov, scientific researcher, Kazan Federal University. 